\title{
Las cañas se vuelven lanzas en Arauco: un torneo indígena en el poema anónimo Las guerras de Chile (cantos IX $\mathrm{X} X$ ) \\ What Begins as a Joke Ends in Tragedy in Arauco: An Indigenous Tournament in the Anonymous Poem Las guerras de Chile (cantos $I X$ and $X$ )
}

Carlos Mata Induráin

Grupo de Investigación Siglo de Oro

Universidad de Navarra

Campus Universitario. Pamplona, 31009

cmatain@unav.es

Orcid ID 0000-0001-6579-5690
Resumen: Este trabajo se centra en el episodio del torneo indígena incluido en los cantos Ix y $\mathrm{x}$ del poema anónimo Las guerras de Chile, en el que se enfrentan las cuadrillas araucanas de Purén y de Catiray, y que a punto está de degenerar en un sangriento combate a muerte. Se analiza su relación con el capítulo sexto de la Primera parte de Las guerras civiles de Granada de Ginés Pérez de Hita (1591), donde se recoge un combate similar entre cegríes y abencerrajes, y se señalan algunos ecos de la épica clásica como, por ejemplo, el catálogo de ejércitos y capitanes.

Palabras clave: Poesía épica americana. Guerra de Arauco. Las guerras de Chile. Ginés Pérez de Hita. Guerras civiles de Granada.
RECIBIDO: 5 DE MARZO DE 2018 ACEPTADO: 22 DE MARZO DE 2018
Abstract: This paper focuses on the episode of the indigenous tournament included in the anonymous poem Las guerras de Chile, cantos IX and $\mathrm{X}$, in which take part two squads of people coming from Purén and Catiray, in the Araucanian region, when the sports fight is about to turn into a bloody fight to the death. It is analysed the relationship with the sixth chapter of the First Part of Las guerras civiles de Granada by Ginés Pérez de Hita (1591), where we found a similar combat between Cegríes and Abencerrajes. Some echos from the classic epic poetry are also mentioned, for example the catalogue of troops.

Keywords: Colonial Epic Poetry. Arauco War. Las guerras de Chile. Ginés Pérez de Hita. Guerras civiles de Granada. 


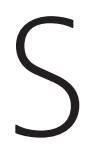
i al acercarnos a la épica colonial americana nos estamos enfrentando a un "género fantasma”, según la expresión empleada por Raúl Marrero-Fente en su reciente monografía sobre el tema (11-30), ${ }^{1}$ creo que podemos convenir también en que se trata de un fantasma que, en las dos últimas décadas, está logrando corporeizarse con cierta frecuencia y bastante intensidad. Buena prueba de ello la tenemos en ese libro de Marrero-Fente, Poesía épica colonial del siglo XVI: historia, teoría y práctica, que ha venido a unirse a otras aportaciones notables, desde la pionera (aunque tardía) monografía de Avalle-Arce, del año 2000, pasando por el volumen colectivo coordinado por Paul Firbas en el 2008, Épica y colonia: ensayos sobre el género épico en Iberoamérica (siglos ХИ у ХИІІ); otro libro colectivo al cuidado de Guillermo Serés y Mercedes Serna, Los límites del océano: estudios filológicos de crónica y épica en el Nuevo Mundo (2009); el estudio del 2016 de José Antonio Mazzotti Lima fundida: épica y nación criolla en el Perú; la sección monográfica "Crónicas y épica de Indias: nuevas lecturas" de la revista Hipogrifo 4.1 (2016), coordinada por Javier de Navascués; o el volumen Viajeros, crónicas de Indias y épica colonial, editado por Mariela Insúa y Jesús Menéndez Peláez (2017). Esto por mencionar solamente monografías o volúmenes colectivos, pero a este corpus crítico habría que añadir, por supuesto, numerosas contribuciones sobre autores y obras particulares en forma de artículos y capítulos de libros.

Pues bien, con este trabajo pretendo una modesta aportación a este campo de los estudios de épica americana, analizando un episodio concreto del poema anónimo Las guerras de Chile. Mi acercamiento permitirá mostrar, creo, que la influencia de la primera parte de las Guerras civiles de Granada de Ginés Pérez de Hita -ya señalada para La Araucana de Ercilla, por ejemplo, por Barbara Fuchs (35-63) $-^{2}$ se detecta también en este otro poema sobre la guerra de Arauco, al menos en ese episodio del torneo indígena inserto en los cantos IX y $\mathrm{x}$. Se trata, como enseguida veremos, de una celebración "deportiva" en el contexto de una fiesta que celebran los indígenas de Arauco que a punto está de degenerar en un sangriento combate a muerte entre las dos cuadrillas participantes de Purén y Catiray, de forma muy similar a lo que sucede en el capítulo sexto de la Primera parte de la obra de Pérez de Hita (1591), donde también las justas que se celebran en la plaza de Bibarrambla de Granada pronto se transfor-

1. Para la épica en el Siglo de Oro ver los trabajos de Pierce, Lara Garrido, Davis y Cacho Casal, coord.

2. La crítica (ver Ajens y, sobre todo, Huidobro Salazar 2011, 2012 y 2017c) ha señalado la presencia de la guerra de Troya como hipotexto del poema y la influencia en él de la Eneida de Virgilio. Para los ecos de la Eneida en la Araucana ver, por ejemplo, Cristóbal. 
man en una lucha a muerte entre los dos bandos enfrentados de cegríes y abencerrajes. "No hay amigo para amigo. / Las cañas se vuelven lanzas", se dice en el célebre romance que ahí se recoge (el que comienza "Afuera, afuera, afuera; / aparta, aparta, aparta, / que entra el valeroso Muza / cuadrillero de unas cañas"), ${ }^{3}$ formulación que llegaría a hacerse tópica. ${ }^{4}$ En el poema americano se expresa que "la burla al punto en veras se convierte" $(723,5)$, frase que no coincide textualmente con el antecedente español, pero que indudablemente tiene el mismo significado. En ambos episodios, la rápida intervención conciliadora de quien había convocado las respectivas fiestas (el Rey Chico de Granada, en un caso, para celebrar el final del Ramadán; el caudillo araucano Anganamón, para conmemorar el aniversario de su liberación del cautiverio en que lo tenían los españoles), metiéndose en medio de las dos cuadrillas para separarlas, logra apaciguar los ánimos antes de que el combate se generalice con resultados nefastos. En ambos casos también la refriega se salda con dos muertos, uno por cada bando en liza (el abencerraje Alabez y Mahomad Cegrí, en Granada; en Arauco, el purenciano Tarucano y Juan Sánchez, un español que se ha pasado al campo indígena). Los puntos de contacto entre ambos episodios no se limitan a esta coincidencia "argumental", sino que en ambos contextos épicos, el granadino y el araucano, el pasaje está al servicio de la descripción idealizada de ese "otro" (ver Todorov, González Cruz y Stoichita) que, aunque enemigo en la realidad histórica, desde la perspectiva literaria puede ser contemplado -como de hecho lo es- con una mirada profundamente idealizada: los indígenas araucanos, igual que los moros granadinos, son portadores de valores positivos propios de los caballeros cristianos: cortesanía, valor, bizarría, etc. Más allá -y a pesar- de la violencia real generada en ambos mundos fronterizos (el reino nazarí de Granada, reducto último de los musulmanes tras siete siglos largos de Reconquista en la Península, y el territorio de Arauco, verdadero "Flandes indiano" al sur del río Biobío, en el extremo austral del continente americano), queda lugar para esa expresión literaria idealizada, y lo que antes fue maurofilia es ahora indiofilia, como ya hiciera notar Avalle-Arce (31).

3. Pérez de Hita, capítulo sexto, "Cómo se hicieron fiestas en Granada, y cómo por ellas se encendieron más las enemistades de los Cegríes y Abencerrajes, Alabeces y Gomeles, y lo que más pasó entre Zaide y la mora Zaida acerca de sus amores", 61-62 (en esta y en las demás citas modernizo las grafías sin relevancia fonética). El romance se incluyó en la segunda parte de la Flor de nuevos y varios romances de Pedro de Moncayo (Barcelona: Jaime Cendrat, 1591, fols. 74r-75r) y en el Romancero general de 1600 (Durán, núm. 88, “Amores de Muza III", 46b-47a).

4. Así, por ejemplo, se menciona en el Quijote II, 12, y lo registra también Correas en su Vocabulario de refranes y frases proverbiales. 
BREVES DATOS SOBRE EL AUTOR Y LA OBRA

Las guerras de Chile (o La guerra de Chile, porque el manuscrito que nos ha transmitido el texto no trae título y se han hecho distintas propuestas al respecto) es un poema épico sobre la guerra de Arauco, formado por más de 7000 versos, que fue escrito en el primer cuarto del siglo XVII (la datación se puede fijar entre 1610 y 1630, aproximadamente). Su autoría es problemática: fue escrito por un poeta-soldado todavía no satisfactoriamente identificado; Medina lo atribuyó al sargento mayor Juan de Mendoza Monteagudo, sacando la edición a su nombre, pero tal atribución está lejos de haber sido probada, por lo que parece preferible seguir considerando el poema anónimo. Pese a contar con una valiosa edición crítica moderna (la de Ferreccio y Kordić del año 1996), ${ }^{5}$ es una obra escasamente conocida y muy poco atendida por la crítica, al menos hasta fechas recientes. ${ }^{6}$ El poema destaca por la abundante utilización de elementos de la tradición clásica (tema estudiado en varios trabajos por Huidobro Salazar), así como por el buen conocimiento que revela de la realidad araucana.

En la obra se describen distintos episodios bélicos de la rebelión mapuche de finales del siglo XVI. Si La Araucana finalizaba con la batalla de Quiapo (1558), la acción de Las guerras de Chile nos traslada a cuarenta años después. El poema trata, concretamente, de la guerra de Arauco entre los años 1598 y 1600: la acción comienza con la batalla (sorpresa, desastre) de Curalaba de 1598, en la que las tropas del $l o n k o^{7}$ Pelantaro (denominado en el poema Pelentaro) matan al gobernador Martín García Óñez de Loyola; se refiere después el envío de refuerzos españoles desde el Perú al año siguiente, 1599, al mando del nuevo gobernador Francisco de Quiñones; y la obra concluye abruptamente con la llegada de los holandeses a Chiloé en 1600 (la expedición corsaria organizada por los hermanos Simón y Baltazar de Cordes, culminada por este tras el fallecimiento del primero). Cabe presuponer que el inconcluso proyecto narrativo del autor/narrador testigo incluiría la alianza de los indígenas con los piratas holandeses y el ataque de estos a Castro, en la Isla Grande de Chi-

5. Todas las citas serán por esta edición (se indican los números de las octavas y los versos dentro de ellas), con ligeros retoques en la puntuación. Otras intervenciones mayores sobre el texto quedan consignadas en nota.

6. Ver los trabajos de Ajens, Barraza Jara, Barros Franco, Cebrián López, ed., Huidobro Salazar, Mata Induráin, Navascués, Silva Galdames, y Triviños/Rodríguez Hernández.

7. Palabra del mapudungún que significa 'cabeza', y por extensión, 'jefe, caudillo, capitán'. 
loé, con la defensa de la ciudad por los españoles (Navascués 2017; ver también Navascués 2016b). ${ }^{8}$

\section{EL TORNEO INDÍGENA}

Pero pasemos ya al episodio concreto del torneo indígena, que constituye el núcleo de mi análisis. Conviene destacar que el poema tiene en su conjunto una estructura episódica, lo que permite deslindar distintas unidades narrativas y de contenido. Pues bien, el segmento anterior acababa con el exordio de Lope de Gamboa a los españoles y el anuncio de las obras de reparación del fuerte de Arauco (en el canto VIII). El episodio del torneo indígena se sitúa a caballo de los cantos IX y X. El IX comienza describiendo los aprestos que se hacen en el fuerte para repararlo (632-37), pero enseguida la focalización narrativa móvil nos traslada al campo araucano:

Mas mientras que, cual suele, se le antoja

venir o no venir al araucano,

será bien que volvamos donde aloja

el campo catiray y el purenciano.

Por dar a los cristianos muerte roja

conté que los cercaron, aunque en vano,

la gran auturidad de Pelentaro

y el juvenil furor de Quelentaro. (638)

Tras mantener el cerco por un tiempo, los indígenas deciden levantarlo (639). Ocurre que ha llegado la primavera y, como cada año, Anganamón, "el señor más rico y más guerrero / de toda la provincia purenciana” (641, 3-4), equiparado a $\operatorname{Marte}^{10}(641,8)$, quiere conmemorar con una fiesta la fecha en que, tiempo atrás -el texto no especifica cuánto-, fuera liberado del cautiverio por su esposa Guaiquimilla (640). El texto recupera ahora la información de su captura y de su posterior liberación. En una ocasión en que, tras pasar todo el día bebiendo (todos sus hombres brindaban, y él hacía la razón a todos),

8. Para más detalles sobre el panorama textual del poema, su autoría y las fuentes, su estructura y un resumen detallado del contenido remito a Mata Induráin 2013.

9. Pelentaro (nombre usado en el poema) o Pelantaro (forma más frecuente, del mapudungún $P e-$ lantarú: 'halcón luminoso') es el caudillo, natural de Purén, que encabezó la segunda rebelión mapuche de 1598; capitaneó, junto con sus lugartenientes Anganamón y Guaiquimilla, la batalla de Curalaba, en la que murió el gobernador Martín García Óñez de Loyola.

10. También se indica que tiene un serrallo de veintiséis mujeres (ver 643, 7-8 y 655, 1-2). 
Anganamón se queda dormido y en sueños se le aparece la imagen de su padre Pailacheo, quien le pide que huya, avisándole: "de tu futuro mal soy adivino, / ya tienes los cristianos a la puerta" (645, 5-6). Anganamón, asustado por la visión, salta del lecho y, en efecto, justo en ese momento es apresado: "con dieciséis heridas se halló el fiero / de odiosos españoles prisionero" (646, $7-8)$. Sus captores lo llevan a la ciudad y allí "en opaca espelunca fue guardado" $(647,8)$, donde le quieren dar "el fin de Policrates" $(647,5) .{ }^{11}$

Las octavas siguientes refieren cómo Anganamón intenta ganarse a sus carceleros con oro, "Haciendo entre los nuestros muy del Creso" $(649,1)$. El dinero repartido hace que le den una prisión dorada, en la que es tratado con mucha consideración ("así era su persona regalada", 651, 6). Se dice, en efecto, que este encierro "en todo al indio noble, sin ultraje, / no le era ya prisión sino hospedaje" (651, 7-8). Pese a todo, el bárbaro $(652,5)$ está inquieto y busca por mil caminos la forma de verse libre. Vigilado con cien ojos de Argos, será su Medea -no su Ariadna- quien le traiga un hilo para sacarlo del laberinto (654). El caudillo araucano tiene veintiséis esposas, todas de igual rango $(655,1-2)$, pero en la cárcel solo le sirve una de ellas, la más bella, Guaiquimilla. Esta trama un plan que consiste en que él salga vistiendo sus ropas femeniles, en tanto que ella queda en su lugar. Anganamón se resiste al principio a usar esta añagaza, pero "venció al robusto al fin la delicada" $(657,5)$ y acepta el plan: "afeminar se deja la figura / y ser como otro Aquiles trasvestido" ${ }^{22}(658,3-4)$, de forma que "el bárbaro salió una dueña hecho" $(658,8)$. El relato se tiñe en este punto con unas pinceladas de humor, pues se refiere que el fiero araucano pasea hacia la salida con tal "aire, talle y contoneo" $(659,1)$, y dando tales miradas a los guardias, "que puso en arma al alma más modesta" $(659,4)$. No será hasta el amanecer cuando se descubra el engaño y, una vez "sabido / el hecho varonil de la hembra pía" (661, 1-2), los españoles dejan ir en paz a Guaiquimilla. Para conmemorar esta sorprendente liberación, Anganamón decide celebrar una "fiesta soberana / en toda la provincia purenciana" (661, 7-8), que se repetirá cada año. Tras esta analepsis informativa que explica la liberación de Anganamón en el pasado -que es el motivo por el que se hace el torneo-, la octava 662 conecta con la

11. Polícrates (570 a.C.-522 a.C.), tirano de Samos, fue condenado a morir crucificado por Oretes, sátrapa de Lidia. El desplazamiento acentual resulta necesario para mejorar el ritmo del endecasílabo.

12. Tetis, sabedora de que su hijo moriría si acudía a la guerra contra Troya, lo mandó a la corte de Licomedes, y allí vivió un tiempo escondido en el gineceo, disfrazado de mujer. 
640, indicando que "el gran Pelentaro" ha decidido "hacerla en Pailachaca ${ }^{13}$ dignamente / con todo el gran concurso de la gente" (662, 7-8). La octava siguiente describe el "fértil valle y abundoso" $(663,1)$ elegido para el encuentro, donde se reúne el "bárbaro ejército" $(663,6)$. Los araucanos cercan con árboles una plaza en cuyos extremos plantan dos estandartes: uno, que representa dos águilas azules sobre campo blanco, reúne a los que vienen de la región de Purén, y otro con un alto monte dibujado, bajo el que se agrupan los de Catiray:

El uno, por las señas imperiales de dos soberbias águilas pintadas, mostraba ser de aquellos las señales, de azul en campo blanco dibujadas; el otro, entre malezas y breñales de pardo sobre verde recamadas, mostraba en forma bien de excelsa cumbre del alto Catiray la pesadumbre. (665)

Así pues, los guerreros reunidos representan a las dos provincias araucanas de Purén y Catiray, ${ }^{14} \mathrm{y}$ la fiesta consiste en que cada bando deberá tratar de capturar el estandarte enemigo, al tiempo que defiende el suyo. Se mencionan las armas que pueden portar "por evitar allí ocasiones" $(667,2)$, a saber: "lanzas por los estremos retostadas, / sin más hierro que aquello y recatones" (3-4), es decir, lanzas cuyas puntas han sido endurecidas al fuego, pero sin ningún tipo de refuerzo metálico (tampoco en los cuentos; más adelante, 689, 3, se insistirá en este uso de "lanzas sin cuchillas"). Los jinetes pueden llevar además mazas colgando en los arzones, quedando a su libre elección el tamaño. Las condiciones del torneo se publican por medio de pregones (668). Se ha construido un tablado sobre doce columnas, alto de veinte gradas, desde donde puede asistir al combate el general Anganamón con su senado, y se ha delimitado una plaza a modo de campo. Hay allí nueve abetos con "cintos de coronas" $(670,4)$ para premiar a los guerreros que más se señalen. Todos los

13. Pailachaca: paraje cercano a Curalaba, donde los araucanos tenían un fuerte.

14. Purén y Catiray son dos regiones de la Araucanía en las que los mapuches ofrecieron fuerte resistencia a los conquistadores españoles. En los primeros tiempos de la conquista (primavera de 1553), Juan Gómez de Almagro fundó en Purén ('tierra de pantanos', en mapudungún), por orden de Pedro de Valdivia, la plaza fuerte de San Juan Bautista de Purén. Catiray (o Catirai) es una zona al sur del río Biobío donde los indígenas, al inicio de la guerra de Arauco, construyeron un pucará (una fortaleza en la cima de una colina). 
combatientes que se hallan presentes desean que salga el sol para entrar en la lid; y lo mismo sucede con el público, que se mantiene expectante deseando asistir al choque. Pasa la noche (octava 673, que incluye abundantes alusiones mitológicas: Lucina, Ericina, el Toro, Arturo y Orión) y, cuando amanece, se junta toda la gente rodeando la estacada y se acercan también los dos bandos contendientes:

Ya entre dudosa sombra y luz incierta, que todo tras cendal se devisaba, la gente, de ningún sueño dispierta, apriesa el estacado rodeaba, que el son de las trompetas dando alerta en forma de batalla les mostraba, puestos por dos contrarios horizontes, venir avecinándose dos montes. (674)

El episodio se construye ahora con un recurso de gran tradición en la épica: el catálogo de las tropas ${ }^{15}$-aquí más bien cuadrillas-, con enumeración primero de los contingentes que vienen de Catiray, mandados por Quelentaro, ${ }^{16} \mathrm{con}$ su estandarte que trae dibujado un monte. La cuadrilla va dividida en tres escuadras, con los piqueros en vanguardia: Longotegua ${ }^{17}$ manda sobre los coyuncheses; vienen luego los catirayes, con su caudillo Quelentaro y su estandarte en el centro, y a su lado Colicheo; ${ }^{18}$ siguen después los molchenes, michilemos, engolanos y otros grupos, comandados por Navalburí. ${ }^{19}$ Importa destacar que se describen con bastante detalle (son seis octavas) sus armas y divisas, igual que su formación para el combate:

Trayendo por espaldas el oriente, junta y en tres escuadras dividida, se vio llegar intrépida la gente

15. Baste recordar el canto II de la Ilíada, con el catálogo de las naves y las tropas (II, 484-93 y II, 786-917, respectivamente), o el mismo catálogo épico en la Eneida de Virgilio (VII, 540-815). Ver especialmente González García y Nicolai.

16. Quelentaro: el nombre de este guerrero, en mapudungún, significa 'cola de traro'.

17. Longotegua: este toqui mapuche (cuyo nombre en mapudungún, Lonko-trewa, significa 'cabeza de perro') era el capitán de los coyuncheses.

18. Colicheo: el nombre de este caudillo significa 'avestruz colorada'.

19. Navalburí: Naguelburi en la Historia general del reino de Chile, Flandes indiano del padre Diego de Rosales, Nabuelburi en las Memorias de los sucesos de la guerra de Chile de Jerónimo de Quiroga. 
que el franco Biobío da bebida, la que el principio ve de su corriente, y la que al fin le ve de su corrida lanzarse al mar del Sur tan resoluto, que más le entra a dar guerra que tributo.

Entraron en vanguardia de piqueros, mostrando su lucida infantería los diestros coyuncheses los primeros, y el diestro Longotegua les regía; armados van de petos los guerreros, que rojas camisetas los cubría; de montes la divisa muestran fuera, marchando treinta en treinta por hilera.

Tras estos, con el orden diferentes, anchos de frente y anchos de costados, siguen los catirayes preminentes en hondo y escuadrón güeco formados; por centro van allí sus combatientes, de solo pardo y verde divisados; lo verde por lo pardo no se pierde, que tapa allí lo pardo el monte verde.

Por punto deste centro, en un tordillo, que todo sobre el freno va afirmado, llevaba el estandarte el gran caudillo, que muestra el monte patrio a cada lado; como una torre firme en un castillo, sobre un fuerte alazán, a su costado, llevaba a Colicheo, que aquel día cazar las mudas águilas quería.

Formando en ronco son rumores vanos, iban acompañando a su estandarte aquellos que los flatos gozan sanos, que el soplador austrino ${ }^{20}$ les reparte:

20. el soplador austrino: el austro, viento cálido del mediodía. 
molchenes, michilemos, engolanos, y otros que hasta Purén tienen su parte, en tierra que su término allí acaba, y el gran Navalburí los gobernaba.

Aquestos, con vistoso y vario arreo, las matizadas flores imitando, iban con tardo paso y contoneo la forma de su ejército cerrando, que, haciendo un semicírculo y paseo, al campo de la prueba se entró, cuando en otras tres escuadras ordenado llegaba el de Aipiñande de otro lado. (675-80)

Sigue después la enumeración de las huestes de Purén y sus caudillos, con Aipiñande a la cabeza y su estandarte, que muestra dos águilas. Como el otro bando, también este aparece "en otras tres escuadras ordenado" $(680,7)$ : vienen primero las gentes de Contavén, Cautén y Curaraba, guiados por Guanocuca; el grueso de esta tropa lo forman los cautenes, comandados por el propio Aipiñande, que va acompañado de otro caudillo, Longonango. Se mencionan las gentes que le siguen, y también a otro jefe, Pailachonte, que manda sobre "cien diestros piqueros" $(686,4)$. La descripción completa ocupa otras seis octavas (681-86), pero copiaré solo las tres primeras:

Mostrando una cohorte tan entera que en más tierra que Ticio se espaciaba, ${ }^{21}$ se vio llegar la gente en delantera de Contavén, Cautén y Curaraba: armados todos van a la ligera, y armado Guanocuca los guiaba, llevando por divisa en las celadas las aves de los rayos respetadas. ${ }^{22}$

21. en más tierra que Ticio se espaciaba: 'en más tierra que aquella en la que Ticio se espaciaba'. Ticio fue un gigante que intentó violar a Leto (o a Artemisa, en otras versiones). Fulminado por Zeus (o bien muerto por las flechas de Apolo y Artemisa), fue castigado al Tártaro, donde dos buitres devoraban eternamente su hígado. Pero aquí se alude más concretamente a su sepulcro, que según Pausanias era un túmulo funerario cuya circunferencia medía aproximadamente la tercera parte de un estadio (unos 200 metros).

22. las aves de los rayos respetadas: las águilas, porque se creía que podían mirar directamente al sol; luego $(683,3)$ dirá "el ave que la luz del sol perdona". 
A imitación de rápido torrente, formando un escuadrón de cuatro lados, iban en la gran manga de esta gente los cautenes de nuevo libertados; cerrados por la forma van de frente $\mathrm{y}$ abiertos por el fondo y circulados: la escuadra de Aipiñande va allí diestra y él va de su blasón haciendo muestra.

En medio de la viva y gran corona, firme sobre un bridón de huello blando, ${ }^{23}$ el ave que la luz del sol perdona la lleva en campo blanco tremolando; en un bayo, cercano a su persona, la suya Longonango va mostrando, que el águila del peto en la ancha espalda la trae de la color de la esmeralda.

Esta descripción de armas y estandartes de los araucanos recuerda bastante lo que sucede en las Guerras civiles de Granada, donde continuamente se mencionan y describen los vestidos (marlotas de brocado o terciopelo, etc.), armas, divisas y motes de los caballeros moros. Por otra parte, cabe recordar que este catálogo de gentes y etnias sigue la huella de la epopeya clásica, especialmente el recuento de tropas inserto en el libro VII de la Eneida y que encontramos también en La Araucana. Me refiero al catálogo de caciques araucanos en las octavas 10-18 del Libro II y, luego, la revista de tropas que hace Caupolicán en el Libro XXI, octavas 26-34 y 40-49 (las octavas 35-39 constituyen un excurso sobre el origen de la piel de caballo marino que viste Gualemo). Y es recurso que aparece, asimismo, en el Purén indómito de Diego Arias de Saavedra, por ejemplo, cuando se enumeran todas las gentes que se han reunido para la fiesta (borrachera) que se describe al final del canto II.

En nuestro torneo indígena, como hemos podido apreciar, los dos bandos han quedado frente a frente y dispuestos a romper la batalla. Anganamón, que preside la fiesta, autoriza la entrada de los guerreros al cercado $(687,7-8)$ y todos aguardan expectantes "el ver el rompimiento horrendo y crudo" (688, 4). Cuando suena la trompeta, parten a encontrarse primero los dos grupos de

23. de buello blando: de blanda pisada, blando en el pisar. 
cien jinetes ("parten los jinetes ciento a ciento", 688, 8). Se refiere a continuación ese primer encuentro de las dos cuadrillas, en el que caen diez montes (es decir, diez guerreros de Catiray) y quince águilas (quince combatientes de Purén). Esta es la descripción del choque:

Los músculos cerrados y rodillas, y a un punto los caballos aguijando, se encuentran con las lanzas sin cuchillas, los montes y las águilas volando; y a un punto de la cumbre de sus sillas diez montes se bajaron derrumbando, y quince de las águilas de un vuelo vinieron a parar todas al suelo. (689)

Tras romper las lanzas los jinetes, entran en combate los portadores de las mazas, mostrándose la lucha muy reñida:

Los otros, que de firmes y membrudos

el ir tras los amigos se perdonan, sin lanzas, por delante los escudos, los unos a los otros se abandonan; de maza todos juegan golpes crudos y todos un soberbio son entonan; de igual valor se muestran todos luego, que no se ve ventaja en aquel juego. (690)

Entra en este momento en combate el jefe de los purencianos, "el hórrido Aipiñande" (691, 8), que maneja como arma "un dentado güeso entero", lo que lo asimila a un pez espada:

Jugando de un dentado güeso entero, cual entre peces lúbrico espadarte ${ }^{24}$ hendiendo por los montes va ligero,

24. lúbrico espadarte: se refiere al pez espada; el adjetivo lúbrico lo entiendo aquí como 'ágil, escurridizo', y no en el sentido de 'lascivo'. Polibio (citado por Estrabón en su Geografía), Plinio el Viejo en su Historia natural, Claudio Eliano en su Historia de los animales o San Isidoro en sus Etimologías, entre otros, además de varios bestiarios medievales, aludieron a la belicosidad del pez espada, presentándolo como monstruo marino capaz de hundir navíos. Aipiñande, armado con su hueso dentado, se mete entre los guerreros catirayes (montes) causando destrozo como el pez espada entre otros peces. 
buscando vista y paso a su estandarte; mas mucho le conviene ser tan fiero, que el ágil Quelentaro, de otro parte, llevando para el suyo la atraviesa, haciendo entre sus águilas va ${ }^{25}$ presa. (692)

Por su parte, Quelentaro, el caudillo de Catiray, no se queda atrás y va destrozando la escuadra de Cautén, donde combate Guaiquimilla, ${ }^{26}$ con maza de pedernal. $\mathrm{Y}$, en efecto, se nos "muestra" a continuación el combate singular entre el campeón del monte, Quelentaro, y el capitán purenciano Guaiquimilla. El destrozo que causa el primero se describe gráficamente con esta acumulación de verbos, recurso usual en las descripciones épicas de combates:

A golpes tan horrendos, que parece que hurta el curso al rayo que allí imita, aturde miembros, brazos entorpece, vigores enflaquece, fuerzas quita, deslumbra vistas, mentes adormece, y adonde encara luego espanto dita: la vida donde toca atemoriza, y hace ver la muerte espantadiza. (693)

"A golpes que tras golpes desembraza / la escuadra de Cautén va destrozando" (694, 1-2), hasta que le sale al paso Guaiquimilla, quien golpea por tres veces con su hacha de pedernal en el acero de Quelentaro, haciendo saltar chispas, pero cuando va a atacar por cuarta vez el guerrero catiray reclama su turno de ataque. Quelentaro descarga, en efecto, un "golpe insano" contra el tiruano (697), que queda reclinado sobre su caballo; Quelentaro quiere herir de nuevo a Guaiquimilla para derribarlo definitivamente, pero entonces Juan Sánchez, "que el gran blasón de Jove sustentaba" (698, 6; o sea, que lucha con los guerreros águilas; es un español que ha desertado en un combate anterior, ver octavas 284-86), hiere de un altibajo en el brazo al "señor del monte" (698, 8). Quelentaro intenta defenderse con un golpe de maza, pero Juan Sánchez pica su caballo y logra zafarse del ataque, no sin resultar alcanzado en la teste-

25. va: tal vez fuera mejor lectura "ya".

26. Guaiquimilla: así se llama una de las esposas de Anganamón, pero aquí es nombre de varón y se refiere a uno de los lugartenientes de Pelentaro. 
ra: "el golpe fue bastante a trabucallo" $(700,5)$, lo que permite a Quelentaro alejarse para recobrar fuerzas.

Asistimos después ("En esto...", 701, 1) a otro combate singular. Se encuentran ahora en el campo el purenciano Longonango y el catiray Colicheo y, "de mancomún probarse deseando" $(701,2)$, florean sus mazas: "ambos son en la fuerza un misón o Anteo ${ }^{27}$ / y a entrambos va un vigor acompañando" (701, 5-6). El texto pondera, en efecto, la complexión de ambos contendientes: Colicheo, de más edad que su oponente, es poco menos que gigante; Longonango, que es mozo, tiene fuerza, destreza y agilidad. Este, que monta un bayo espléndido, lleva la ventaja en la pelea y da un gran golpe a Colicheo en el almete con su maza:

Montando el ancho escudo que ante el pecho

el fuerte dueño firme lo tenía,

la maza al limpio almete fue de hecho

haciendo repentina batería: ${ }^{28}$

gran parte del crestón quedó deshecho

y el cimero del monte que allí había

voló en átomos vuelto tan sin cuento,

que no los viera un lince ir por el viento. (704)

Sin embargo, Colicheo consigue reponerse y responde con un golpe tremendo en el yelmo de Longonango; este intenta defenderse con su escudo, pero no es suficiente para detener la fuerza del ataque:

Delante el ancho escudo, aquel, güero, ${ }^{29}$

a recibir el golpe lo abandona,

mas baja a dar sobre él un roble entero,

y sobre el yelmo al fin se lo abaldona;

perdió el vigor de vivo verdadero,

no le quedó sentido en la persona,

27. Este es verso largo. Ferreccio y Kordić sugieren en su nota que "misón quizá esté por misio, el pueblo de la Misia del Asia Menor [...], considerado en sus orígenes gente vigorosa". En la mitología griega, Anteo es un gigante, hijo de Neptuno y de la Tierra, que fue vencido por Hércules. De él se dice que vivía en Libia, más concretamente en la región desértica de Irasa, al este de Cirene, por lo que no veo clara la relación con Misia, región situada en la parte noroccidental de la península de Anatolia. Otra posibilidad sería editar "un mismo Anteo", que sería enmienda ope ingenii.

28. batería: aquí vale 'destrozo'.

29. güero: por buero 'vano, inútil' (dada la tremenda fuerza del golpe). 
que el alma, temerosa y encogida,

se los llevó ${ }^{30}$ al erario de la vida. (706)

La descripción de este combate singular se prolonga con nuevas alternativas a lo largo de varias octavas: Longonango casi se desmaya ("quedó como perdido un poco el seso", 707, 2); sin embargo, la maza de Colicheo ha quedado rota, circunstancia que aprovecha el purenciano para reponerse: así, embistiendo a su rival con su caballo, lo ataca con su maza. Colicheo, por su parte, trata de derribarlo; para ello tira de las riendas del bayo de su atacante, que escapa corriendo hasta que choca con la empalizada y derriba por tierra a su jinete. Ocurre entonces -llegamos al punto de inflexión del episodio- que el español Juan Sánchez logra recuperar el caballo, que corría suelto, y se lo lleva, mientras Longonango sale corriendo tras él llamándolo ladrón: "Juan Sánchez, que rocín lleva a contento, / lo escucha cual si escucha un papagayo" (716, 3-4), para volver al rato montando el bayo de Longonango al torneo, "que ya con más rigor de cada lado / estaba en este punto más trabado" (716, 7-8). Este suceso del robo del caballo constituye el primer elemento distorsionador que hace que se empiece a gestar la tragedia. La octava siguiente insiste en esa idea de que el combate está reñido:

Igual de entrambas partes se contiende, que el gran valor a todos los iguala: de aquesta Guanocuca fiero ofende, de aquella Longotegua se señala; mas Quelentaro en esto, que pretende dejar sin los valientes su gran ala, viéndolo entre los suyos andar fiero, cerró con un revés a un venturero. (717)

Nótese el empleo de esta palabra, venturero (aventurero), ${ }^{31}$ que remite claramente al léxico de los torneos caballerescos (González Cuenca). Este léxico del duelo y los desafíos se reitera a lo largo de todo el episodio: mantenedor $(642,6)$, aventureros $(666,2)$, venturero $(717,8)$, campo $(671,6)$, estacado $(674$,

30. se los llevó: la sintaxis pediría "se la llevó", si el antecedente es (como parece) alma.

31. Palabra que Ferreccio y Kordić no explican bien: "venturero = aventurero 'insolente, atrevido'. Los registros dan este valor para los ss. XVIII y siguientes". En realidad, el caballero aventurero era el que entraba en un torneo o justa de forma voluntaria, por contraposición al mantenedor, que era encargado de mantener el combate. 
4), etc. Pero el torneo "deportivo" pronto se va a transformar en encarnizado combate campal. "Vemos" ahora que Quelentaro ataca a Tarucano y lo hiere, y el caballo lo saca contra las plantas que delimitan el cercado. Suceso casual este que, sin embargo, va a ser el detonante que cambie el rumbo de las cosas. Ocurre, en efecto, que:

Estaba a tal sazón allí arrimada la lanza de un bisoño, reluciente: a aquesta el de memoria trasegada echó la airada mano, y de repente veloz vuelve buscando a la estacada a aquel que le atronó la loca mente: violo con Aipiñande careado y embístele la lanza en un costado.

Por donde el espaldar hace juntura, él, impaciente, causa de su yerro, la lanza enristra de la apuntadura, que no se le acordó que lleva hierro; el hierro abrió en la carne sepultura y en medio del ijar hizo su entierro: el alma, viendo abierta la salida, al mozo se le puso en la herida. (719-20)

Tarucano coge esa lanza y, sin darse cuenta de que tiene punta de hierro ("que no se le acordó que lleva hierro", 720, 4), ${ }^{32}$ la arroja contra Quelentaro, hiriéndole en la espalda; este, "de la iracunda Némesis movido" ${ }_{33}(721,2)$, se revuelve contra su atacante y con un golpe de maza le abre la cabeza. Aipiñande, al ver que Quelentaro ha matado a uno de los suyos, ordena que muera el agresor: "-Matallo -les apura-, pues ha muerto. [...] Aqueste, pues ha muerto, ¡muera, muera!" (722, 5 y 8). Ahora ya "No hay amigo para amigo; / las cañas se vuelven lanzas", como sucede con los cegríes y abencerrajes en la fiesta que se celebra en la plaza de Bibarrambla en el capítulo sexto de la Primera parte de las Guerras civiles de Granada:

32. En cambio, en el relato de Pérez de Hita, Mahomad Cegrí toma consciente y voluntariamente a su criado "una lança con un hierro muy agudo y penetrante hecho en Damasco, de fino temple" (60).

33. Entre los griegos, Némesis era la diosa de la justicia, y también de la venganza. 


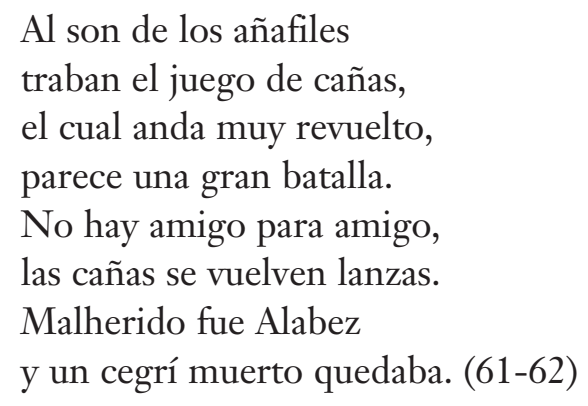

En nuestro texto, las palabras exactas que aparecen son: "la burla al punto en veras se convierte" $(723,5)$. En este contexto, el término burla lo debemos entender en un sentido amplio, como 'simulacro', 'juego' o 'pasatiempo'. Esto es, la lucha, que hasta ese momento había sido una diversión, un ejercicio bélico amistoso en el que las dos cuadrillas de Purén y Catiray rivalizaban en mostrar su fuerza y destreza, se transforma en un combate real, sangriento, a muerte, que al punto se va a generalizar, como muestran estas tres octavas:

Gritando: “iMuera, muera, dalde muerte!”, embiste por matar al mozo luego; pero el mozo feroz, que es ya una muerte, cerró también con él, de rabia ciego: la burla al punto en veras se convierte y de ambas partes, ya encendiendo el fuego, se embisten y, a la voz que los altera, aquí suena matar, acullá muera.

La voz acá y allá se comprehende y la infernal discordia allí arribando envuelta en ira bélica la estiende, a un punto el gran cercado rodeando; en furia el gran ejército se enciende $\mathrm{y}$ a las vecinas armas aguijando, la gente en tropa ya de cada parte se mueve a dar socorro a su estandarte.

De acá y de allá, feroz como se halla, al iracundo son que la discorda se arroja en el cercado tal canalla, que con su propio estrépito se asorda; suenan las trompas, suenan a batalla, 
y a la señal que al trance los concorda, cerrando por dos partes va el gentío:

aquí suena Cautén, allí Biobío. (723-25)

Como escribe Trujillo, "el torneo era, ante todo, la simulación deportiva de una batalla" (342), pero aquí la competición deportiva deja paso ahora a una batalla real, igual que sucede en el episodio granadino. Hay, eso sí, una diferencia fundamental entre ambos textos: en Arauco la contienda se vuelve sangrienta como resultado de un par de sucesos circunstanciales (primero, el robo del caballo de Longonango por Juan Sánchez y luego, el hecho de que Tarucano tome de forma no premeditada una lanza con punta metálica -"que no se le acordó que lleva hierro", 720, 4- que estaba arrimada a la empalizada), en tanto que en las Guerras civiles de Granada se trata de un plan de venganza premeditado de los cegríes, urdido por Mahomad Cegrí, ya que están resentidos por los amores de Zaide con Zaida y también por ciertas palabras despectivas dichas por el Malique Alabez en un sarao anterior. ${ }^{34}$ En efecto, Mahomad Cegrí dispone que sus hombres acudan a la fiesta "muy bien aderezados de armas y jacos fuertes debajo de nuestras libreas" (54). Otra diferencia es que en el episodio araucano no entra en modo alguno el componente amoroso, en tanto que en el granadino sí que se pondera la importancia de las damas que asisten a la contienda, los favores amorosos entregados a sus enamorados, etc.

Así, en este momento culminante en que el combate se ha generalizado, se cierra el canto IX. El X se abre con la intervención conciliadora del caudillo Anganamón, que con la infantería de Purén se interpone entre los dos bandos combatientes: "él todo junto con sus Martes" (727, 5), valga decir con otros caudillos principales, se mete en medio de las cuadrillas (igual que hace el Rey Chico de Granada en el relato de Pérez de Hita), ${ }^{35}$ manda detener a los por-

34. "Finalmente por esto [los amores de Zaide y Zaida], y por las palabras que el Malique Alabez había hablado en el sarao, y Zulema Abencerraje, todos los Cegríes y Gomeles y Mazas y los de su bando quedaron mal enojados y con malos propósitos, propuesta la venganza dello..." (52-53). Mahomad Cegrí explica a los suyos en qué consiste su traidor plan: "Y para esto estemos todos advertidos que el día del juego de las cañas vamos ['vayamos'] todos muy bien aderezados de armas y jacos fuertes debajo de nuestras libreas [...] Y si caso fuere que por la divisa azul nada se les diere en el juego de las cañas, a las segundas vueltas por cañas les tiraremos agudas lanzas, que harto de mal será si algún abencerraje no cayere" (54).

35. "El Rey, que la escaramuza sangrienta vido, no sabiendo la causa dello, a muy gran priesa se quitó de los miradores y fue a la plaza, subiendo sobre una hermosa y bien aderezada yegua, dando voces: «iAfuera, afuera!»; llevando un bastón en la mano, se metió entre los bravos caballeros que andaban muy encendidos en la batalla que hacían. Acompañaron al rey todos los más principales caballeros de Granada, ayudando a poner paz" (60-61). Como puede apreciarse, la coincidencia con lo que sucede en Arauco es muy notable, incluso en pequeños detalles. 
tadores de los estandartes y llega hasta donde están combatiendo Quelentaro y Aipiñande, que es quien va llevando la peor parte: "Anganamón, ligero cuanto pudo, / metiose entre los dos a ser su escudo" (728, 7-8). Sabe que existe una gran amistad entre ambos, y sin embargo allí los oye baldonarse mutuamente de aleves. Siguen las palabras de reproche de Aipiñande a Quelentaro:

"Tú, tú -dice Aipiñande resoluto-

has sido quien, movido de injusticia,

rompiste de placer el estatuto

faltando al homenaje de amicicia;

tú has hecho un amicidio, disoluto,

en ese que declara tu malicia,

en ese que, aunque muerto, sensitivo,

pidiendo está venganza a mí, que vivo.” (730)

Quelentaro replica que los dos, Aipiñande y Tarucano, han sido aleves, y que este último ha actuado traidoramente al echar mano de una lanza con hierro. Su "vengadora maza" $(732,1)$ dejará la verdad averiguada, pero antes quiere dar otra prueba de la traidora mala fe de los contrarios, mostrando la herida recibida en su espalda, "y a un punto, revestido en furia grande, / se traba en nueva lid con Aipiñande" (732, 7-8). Será necesaria una nueva intervención conciliadora de Anganamón, y su "gran auturidad" $(733,4)$, para apaciguar los exaltados ánimos y evitar que la lid se convierta en un "combate ciego":

Confusa y nueva lid se enciende a un punto,

y hubiera a un punto allí un combate ciego,

mas llega el general y, todo junto,

su gran auturidad baraja el juego;

dichoso fue en llegar a tan buen punto,

que, al juvenil furor opuesto luego,

el ímpitu del mozo en sí sostuvo

y a ruegos, más que a fuerza, lo detuvo. (733)

Anganamón le hace ver a Pelentaro que está herido y que la llaga más quiere medicina que furor intrépido; por ello le pide que se retire a su tienda, asegurándole que él permanecerá allí para enmendar el daño. Quelentaro, aunque a regañadientes, arroja la maza y se va, afligido por no haber podido llevar a cabo su venganza. Los generales aguardan, confundidos, el desenlace del "inorado caso" $(736,2)$. En efecto, queda por resolver todavía el segundo asunto, el robo del bayo de Longonango por parte de Juan Sánchez. El joven arauca- 
no se acerca al español y lo derriba al suelo de una tremenda puñada, al tiempo que lo llama "ladrón de mala raza" $(737,3)$. El golpe es tan fuerte que Juan Sánchez queda muerto. Longonango grita que si hay alguien que quiera ser valiente y vengarlo, que se presente allí, "que castigar un malo siempre es bueno" $(738,8)$. Esperará a quienquiera que acuda en el campo que remata el valle. Este suceso deja asombrados a todos, y más a Pelentaro, que se enciende en ira y, olvidado de que a su arnés le falta el grueso de la defensa, acude presuroso dispuesto a la venganza: "y así a vengar la injuria se abandona / que piensa allí ser hecha a su persona” (740, 7-8). Justo cuando va a lanzar su caballo contra Longonango, Rapigüeno, un "viejo providente" ${ }_{36}(741,3)$, detiene al "mozo embebecido" $(741,2)$. El anciano le dice que es fénix que ha resucitado de las cenizas de la patria, y que el mal que va a atajar no requiere hierro, sino ungüento, al tiempo que le pide que no acabe con una buena lanza de las suyas. En realidad, sanciona Rapigüeno, lo que ha hecho el mozo Longonango al matar a Juan Sánchez ha sido ejecutar una pena justa, y no un desacato a su persona. Además, si el español fue traidor, porque vendió a su gente, bien habría podido traicionarlos también a ellos, llegado el caso. Conviene, pues, concordar a los dos bandos, a Quelentaro y a Aipiñande: si Tarucano hizo un tuerto -razona el anciano-, ya lo ha pagado con su muerte. Lo que deben hacer es aunarse y atacar el fuerte del contrario español, de forma que "se dé fin a la impresa en quien se encierra / la cara libertad de nuestra tierra" (750, 7-8). El buen consejo del viejo obra bien en el general, que hace señor del caso a Quelentaro. Finalmente, este marcha al frente de su ejército de Catiray, dejando desmembrado al purenciano. Los varones entran en concejo y votan volver a Purén:

Hubo un arenga larga de razones $\mathrm{y}$ un caos de pareceres diferentes, largas para cifrarse entre diciones y más para contarse a los leyentes; mas la resolución, por opiniones, fue que a Purén partiesen diligentes, de do, de gente el campo reforzado, volviese a proseguir lo comenzado. (753)

36. Rapigüeno: señor de las Tierras Bajas de Purén, segundo del anciano jefe guerrero Paillamacho, que a su vez será sucedido cuando muera por Millacalquín. 
Lo que viene a continuación forma parte ya de un episodio narrativo distinto: el mago (machi) Pangalino los detiene y se ofrece para resolver las cosas de otra manera, asegurando que traerá una gran sequía que aniquile a los españoles... Pero esta es ya otra historia: la sequía llegará, en efecto, pero será contrarrestada con una intervención de orden sobrenatural, un "aguacero santo soberano" $(816,7)$, que salva milagrosamente a los españoles (ver un análisis de este episodio en Mata Induráin 2015).

\section{CONCLUSIÓN}

Ya he mencionado que el poema de Las guerras de Chile presenta una estructura episódica, fragmentaria, característica que ha sido destacada por Huidobro Salazar, quien comenta que esta obra, al igual que el Purén indómito, se caracteriza por

la fragmentación del relato, aquella que David Quint, a partir del análisis de Farsalia, ha identificado con las obras propias de la épica de la derrota. El relato, fragmentario y episódico, daba la impresión de que lo que se narraba era una historia sin un final cierto, cuya única certeza era la violencia de la guerra. (2017b, 193)

Algunos otros estudiosos (Barraza Jara, Ajens...) han señalado también el tono crítico del poema con respecto a la conquista del territorio araucano, su visión nada triunfalista de los hechos narrados: no hay un héroe español que protagonice el relato, se describe esa violencia enquistada durante décadas en el territorio de Arauco, incluso se muestran varias derrotas de los españoles.

En este contexto, ¿cuál podría ser el sentido de este episodio del torneo indígena, en el que no intervienen los españoles? Es evidente, en primer lugar, que estamos ante un elemento que contribuye al ornato retórico-literario del poema. En él apreciamos claros ecos de la epopeya clásica. De la épica provienen diversos motivos como el catálogo de los ejércitos combatientes (aquí cuadrillas del torneo), con la mención de sus armas y divisas, o la descripción de los combates y duelos singulares, ${ }^{37}$ presentes igualmente en La Araucana y

37. Cabe destacar la abundante utilización del léxico propio de la milicia y la guerra (piqueros, flecheros, maceros, arreo, petos, camisetas, celadas, arnés, espaldar, yelmo, almete, testera, cimero, crestón, sillas, arzones, lanzas, escudos, maza, florear mazas, enristrar, altibajo, bilera, escuadras, cohorte, escuadrón, manga, blasón, pendón, estandarte...) y, más específicamente, del ámbito de la caballería y los torneos (campo, palestra, estacado, hacer plaza, campión, venturero, aventureros, mantenedor, etc.). 
en el Purén indómito. De las Guerras civiles de Granada proviene el motivo concreto de "las lanzas se vuelven cañas", formulado aquí como "la burla al punto en veras se convierte" $(723,5)$. No olvidemos que las tierras fronterizas de Granada y las de Arauco -como la ciudad de Troya en la Antigüedad- son espacios asociados a la guerra, una dura y sangrienta guerra prolongada en el tiempo, pero en cuya plasmación literaria es posible la idealización del contrario, del enemigo, del "otro". Aquí la maurofilia del relato de Pérez de Hita deja paso a la indiofilia del anónimo autor del poema chileno.

Este pasaje coadyuva igualmente a la construcción idealizada de los personajes araucanos, que quedan retratados una vez más como valientes, belicosos, nacidos para la guerra, caballeros dispuestos a mostrar su valor no solo en el combate contra el enemigo, sino en este simulacro de batalla que es el torneo. En otro orden de cosas, la crítica ha destacado el alto valor documental del poema, que revela un amplio conocimiento por parte del autor -quienquiera que fuese- de la realidad araucana, del entorno geográfico y sus gentes. ${ }^{38}$ En sus distintos cantos, Las guerras de Chile documenta las armas empleadas por los indígenas, sus estrategias y técnicas de combate, etc. Se explica, por ejemplo, que al principio, cuando la llegada de Pedro de Valdivia al sur de Chile, temían a los caballos y las armas de fuego de los españoles (Silva Galdames 74):

A Valdivia el primero se rindieron, creyendo que eran dioses sus soldados que de los puros aires descindieron rigiendo los caballos alentados. $(58,1-4)$

Sin embargo, pronto asimilaron las armas y las técnicas militares de los conquistadores, y también el empleo de los caballos, convirtiéndose enseguida en hábiles jinetes:

Hanse hecho con próvida destreza jinetes de ambas sillas ${ }^{39}$ desenvueltos por el efecto grande y ligereza de los caballos ágiles revueltos; sacan la utilidad de su presteza

38. "El conocimiento de costumbres y creencias nativas, al menos en la zona fronteriza, de que hace gala el vate parecería indicar que estuvo muchos años en contacto con ellos" (Silva Galdames 73).

39. de ambas sillas: o sea, a la brida y a la jineta, las dos formas clásicas de montar a caballo. 
y en trances más que partos son resueltos: ${ }^{40}$

en unos a vencer, si importa, aspiran,

y en los otros dañando se retiran. (28)

En este torneo tenemos una magnífica prueba de esa asimilación por parte de los indígenas de la caballería (aquí combaten los jinetes araucanos nada menos que "ciento a ciento", 688, 8; ver Checa).

Por último, este episodio sirve igualmente para poner de manifiesto la heterogeneidad del pueblo mapuche, ${ }^{41}$ pues aunque en el poema se habla del estado de Arauco, este se halla formado por distintos territorios o provincias, cada una con sus distintos grupos étnicos, clanes o linajes familiares, los cuales solían dar la guerra en su propio distrito (lo que no impedía que a veces se aliaran para hacer frente al enemigo común en empresas de mayor aliento). $\mathrm{O}$ que, en ocasiones, como hemos podido comprobar aquí, una chispa, un imprevisto suceso casual, bastase para hacer estallar las tensiones y rivalidades internas. Sea como sea, tanto en la guerra contra el invasor español para defender denodadamente su libertad e independencia como en esta escaramuza bélica entre ellos (cuando "la burla" o simulacro del torneo festivo "al punto en veras se convierte"), los araucanos dan sobradas muestras de su valor, de su habilidad en el manejo de las armas, en suma, de su natural inclinación al ejercicio de la guerra.

\section{OBRAS CITADAS}

Ajens, Andrés. "Aged War. On an Anonymous Poem of Uncertain Date”. Poetry After the Invention of América: Don't Light the Flower. New York: Pallgrave Macmillan, 2011. 19-23.

Anónimo. La guerra de Chile. Eds. Mario Ferreccio Podestá y Raïssa Kordić Riquelme. Santiago de Chile: Universidad de Chile, 1996.

Arias de Saavedra, Diego. Purén indómito. Ed. Mario Ferreccio Podestá. Estudio preliminar: Mario Fernández. Santiago de Chile: Biblioteca Nacional de Chile/Concepción: Universidad de Concepción, 1984.

Avalle-Arce, Juan Bautista de. La épica colonial. Pamplona: EUNSA, 2000.

40. más que partos son resueltos: los partos eran excelentes jinetes, como se indica en el propio poema en una apostilla marginal.

41. Silva Galdames destaca que el autor expresa esta heterogeneidad mapuche "en una visualización poco habitual en cronistas y burócratas de su época, que persistían en ver a los «indios de Chile» como una nación al estilo de los surgientes estados europeos" (73). 
Barraza Jara, Eduardo. "El Purén indómito y La guerra de Chile: los vencedores vencidos". De "La Araucana" a "Butamalón": el discurso de la conquista y el canon de la literatura chilena. Valdivia: Universidad Austral de Chile, 2004. 202-08.

Barros Franco, José Miguel. "Incursión historiográfica en La guerra de Chile". La guerra de Chile. Eds. Mario Ferreccio Podestá y Raïssa Kordić Riquelme. Santiago de Chile: Universidad de Chile, 1996. 33-62.

Cacho Casal, Rodrigo, coord. La poesía épica en el Siglo de Oro. Criticón 115 (2012).

Cebrián López, Eduardo, ed. Anónimo. Doce cantos sobre Chile. Santiago de Chile: Puerto de Palos, 2007.

Cervantes, Miguel de. Don Quijote de la Mancha. Ed. Instituto Cervantes dirigida por Francisco Rico. Barcelona: Instituto Cervantes/Editorial Crítica, 1998.

Checa, Jorge. "Los araucanos y el arte de la guerra". Prolija memoria 2.1-2 (2006): 25-51.

Correas, Gonzalo. Vocabulario de refranes y frases proverbiales. Ed. digital Rafael Zafra. Madrid: Iberoamericana/Frankfurt am Main: Vervuert, 2000.

Cristóbal, Vicente. "De la Eneida a la Araucana". Cuadernos de Filología Clásica: estudios latinos 9 (1995): 67-102.

Davis, Elizabeth. Myth and Identity in the Epic of Imperial Spain. Columbia/ Londres: Missouri UP, 2000.

Durán, Agustín, ed. Romancero general. Vol. 1. Madrid: Atlas, 1945.

Ercilla, Alonso de. La Araucana. Ed. Isaías Lerner. Madrid: Cátedra, 1993.

Firbas, Paul, ed. Épica y colonia: ensayos sobre el género épico en Iberoamérica (siglos ХVI у XVII). Lima: Universidad Nacional Mayor de San Marcos, 2008.

Fuchs, Barbara. Mimesis and Empire: The New World, Islam, and European Identities. Cambridge/New York: Cambridge UP, 2001.

González Cruz, David, ed. Pueblos indígenas y extranjeros en la monarquía bispánica: la imagen del otro en tiempos de guerra (siglos XVI-XIX). Madrid: Sílex, 2011.

González Cuenca, Joaquín. "Espectáculos nobiliarios de riesgo: el torneo y sus variantes". Historia de los espectáculos en España. Coords. Andrés Amorós y José María Díez Borque. Madrid: Castalia, 1999. 487-506.

González García, Francisco Javier. El catálogo de las naves: mito y parentesco en la épica homérica. Madrid: Clásicas, 1997.

Homero. Ilíada. Ed. y trad. Antonio López Eire. Madrid: Cátedra, 1989. 
Huidobro Salazar, María Gabriela. "Tradición clásica en Las guerras de Chile”. Atenea 503 (2011): 133-45.

Huidobro Salazar, María Gabriela. "Ecos de la Eneida en el anónimo poema La Guerra de Chile". Cuadernos de Filología Clásica: estudios latinos 32.2 (2012): 335-45.

Huidobro Salazar, María Gabriela. "El tópico del incendio en la épica sobre la guerra de Arauco: una mirada crítica a la conquista de Chile". Anales de Literatura Chilena 20 (2014): 13-32.

Huidobro Salazar, María Gabriela. El imaginario de la guerra de Arauco: mundo épico y tradición clásica. Santiago de Chile: FCE/Universidad Andrés Be1lo, 2017a.

Huidobro Salazar, María Gabriela. "El retrato del bárbaro y el concepto de barbarie en la épica sobre la guerra de Arauco en el siglo XVI". Hipogrifo 5.2 (2017b): 169-98.

Huidobro Salazar, María Gabriela. "Recursos literarios de la épica clásica para la representación de la guerra de Arauco en el siglo Xv1". Edad de Oro 36 (2017c): 159-73.

Insúa, Mariela, y Jesús Menéndez Peláez, eds. Viajeros, crónicas de Indias y épica colonial. New York: IDEA, 2017.

Lara Garrido, José. Los mejores plectros: teoría y práctica de la épica culta en el Siglo de Oro. Málaga: Universidad de Málaga, 1999.

Marrero-Fente, Raúl. Poesía épica colonial del siglo XVI: historia, teoría y práctica. Madrid: Iberoamericana/Frankfurt am Main: Vervuert, 2017.

Mata Induráin, Carlos. "Una aproximación a Las guerras de Chile, poema épico anónimo del siglo XVII". Taller de Letras número especial 3 (2013): 153-70.

Mata Induráin, Carlos. "Episodios sobrenaturales en textos coloniales chilenos: el «aguacero santo soberano» en el poema Las guerras de Chile (cantos X y XI)". Romance Notes 55, special issue (2015): 63-72.

Mazzotti, José Antonio. Lima fundida: épica y nación criolla en el Perú. Madrid: Iberoamericana/Frankfurt am Main: Vervuert, 2016.

Navascués, Javier de, coord. "Crónicas y épica de Indias: nuevas lecturas". Sección monográfica de Hipogrifo 4.1 (2016a).

Navascués, Javier de. "Alteridad y mímesis del pirata en la épica colonial". Hipogrifo 4.1 (2016b): 43-63.

Navascués, Javier de. "La materia de los piratas de la épica chilena: Purén indómito y La guerra de Chile". Hipogrifo 5.2 (2017): 153-68. 
Nicolai, Roberto. "Il catalogo dei popoli italici nell'Eneide (7, 623-817) e i suoi modelli”. Mélanges de l'Ecole française de Rome. Antiquité 129.1 (2017): 1931.

Pérez de Hita, Ginés. Guerras civiles de Granada: primera parte. Reproducción de la edición príncipe del año 1595 publicada por Paula BlanchardDemouge. Madrid: Imprenta de E. Bailly-Baillière, 1913.

Pierce, Frank. La poesía épica del Siglo de Oro. Trad. J. C. Cayol de Bethencourt.

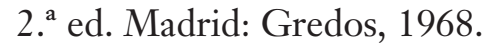

Quint, David. Epic and Empire: Politics and Generic Form from Virgil to Milton. Princeton: Princeton UP, 1993.

Serés, Guillermo, y Mercedes Serna Arnáiz, coords. Los límites del océano: estudios filológicos de crónica y épica en el Nuevo Mundo. Bellaterra: Centro para la Edición de los Clásicos Españoles, 2009.

Silva Galdames, Osvaldo. "La guerra de Chile como fuente histórica". La guerra de Chile. Eds. Mario Ferreccio Podestá y Raïssa Kordić Riquelme. Santiago de Chile: Universidad de Chile, 1996. 63-79.

Stoichita, Victor I. La imagen del otro: negros, judios, musulmanes y gitanos en el arte occidental en los albores de la Edad Moderna. Trad. Anna Maria Coderch. Madrid: Cátedra, 2016.

Todorov, Tzvetan. La conquista dell'America: il problema dell'“altro". Torino: Einaudi, 1992.

Triviños, Gilberto, y Mario Rodríguez Hernández. "La clausura de la epopeya en La guerra de Chile". Estudios filológicos 31 (1996): 39-56.

Trujillo, José Ramón. "El espacio de la proeza y sus motivos narrativos: justas, torneos y batallas en la materia artúrica hispánica”. Revista de poética medieval 26 (2012): 325-56.

Virgilio Marón, Publio. Opera. Ed. R. A. B. Mynors. Oxford: Oxford Classical Texts, 1969. 